\title{
Detecting the Glyphosate Contamination in Manihot esculenta (Variety Alu Peradeniya) Grown in Sri Lanka
}

\author{
Amarasiri M.C.K., Godakumbura P.*and Prashantha M.A.B. \\ Department of Chemistry, Faculty of Applied Sciencs, University of Sri Jayewardenepura, Sri Lanka \\ *pahanig@gmail.com
}

\begin{abstract}
Cassava is a popular local yam in Sri Lanka which is an important source of energy and a raw material for snack foods. A survey on cassava cultivation revealed that the most common cassava variety is "Alu Peradeniya" and there is a heavy usage of "Glyphosate" as a weedicide during the cultivation. This study was done to detect the contamination of glyphosate in outer peel, inner peel and starchy flesh of the M. esculenta variety as it directly relates with the human health.
\end{abstract}

Tubers of variety "Alu peradeniya" were collected from local farmers from Colombo, Matara, Embilipitya, Galle, Anuradhapura and Ampara in Sri Lanka and control samples without glyphosate and with glyphosate were cultivated in my home in Mattegoda, which belongs to Colombo district. Glyphosate levels in samples were determined by a spectroscopic method using ninhydrin in the presence of sodium molybdate to give a Ruhemann's purple product having visible absorption at $570 \mathrm{~nm}$ and further confirmation of results was done by using LCMS at ITI.

Due to the presence of free amino acids in inner peel and starchy flesh, ninhydrin test for glyphosate was limited to the outer peel of the tuber because ninhydrin gives a positive response with amino acids. Outer peel of the control sample with glyphosate showed a concentration of $10.1 \mathrm{mg} / \mathrm{kg}$, which was the least concentration detected. The highest concentration of the glyphosate in outer peel was observed in one of the Colombo samples, which was $20.1 \pm 0.1$ $\mathrm{mg} / \mathrm{kg}$. The amount was recorded twice than that of the recommended amount. Samples from Galle and Matara showed similar values as control sample with glyphosate, which has grown having the permitted amount. Outer peels of some of the samples did not show positive responses indicating that the usage of glyphosate is minimum or absence of glyphosate usage. Further confirmation using LC-MS for selected samples reveals that there is a possibility of penetration of glyphosate among the tuber because both inner peel and starchy flesh were positive for the detection of glyphosate. Due to the repetitive application of Glyphosate and its long half-life in the soil, the impact of the agrochemical on environment and on human life is becoming more pertinent.

Keywords: Cassava, Glyphosate, Penetration

Proceedings of the International Forestry and Environment Symposium 2016, Department of Forestry and Environmental Science, University of Sri Jayewardenepura, Sri Lanka. 